DOI: 10.18468/letras.2017v7n2.p135-160

\title{
AS DUAS GRAMÁTICAS DE TUDO E AS VARIEDADES DO \\ PORTUGUÊS AFRO-BRASILEIRO
}

Juliana Batista Trannin ${ }^{1}$

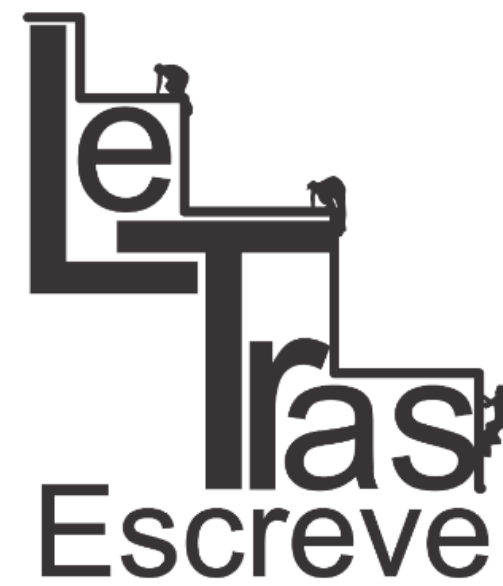

(ISSN 2238-8060)

Abstract: The aim of this work is to study the syntax of the quantifier tudo and todo(s) 'all' in African-Brazilian Portuguese, in comparison to Common Brazilian Portuguese, in the generative grammar framework. I put forward that the same variation between such quantifiers is found in these two groups of Portuguese varieties. Therefore, the data analysis shows that Afro-Brazilian dialects present one out of two possible grammars of tudo, as much as Common Brazilian Portuguese: one with a restrictive distribution, another so-called "radical". In dialects with rich morphology, the syntax of tudo is similar to the one found in the restrictive grammar. In other dialects which exhibit poor morphology, the usage of tudo is widespread, as in the "radical" grammar.

Keywords: Quantifiers. Syntax. Afro-Brazilian Portuguese.

\section{Introdução ${ }^{2}$}

No português brasileiro (PB), é comum o uso da palavra tudo, uma forma neutra, nos mesmos contextos do quantificador universal todos, como na sentença Os menino tudo comeram o bolo. Essa vari-

\footnotetext{
${ }^{1}$ Doutora em Linguística pela Universidade Estadual de Campinas. E-mail: julianatrannin@gmail.com.

2 Este texto apresenta os principais resultados do capítulo 4 da minha tese de doutorado (TRANNIN, 2016). Agradeço a dois pareceristas anônimos pelas preciosas correções a uma versão anterior deste texto.
}

https://periodicos.unifap.br/index.php/letras

Macapá, v. 7, n. 2, 20 semestre, 2017. 


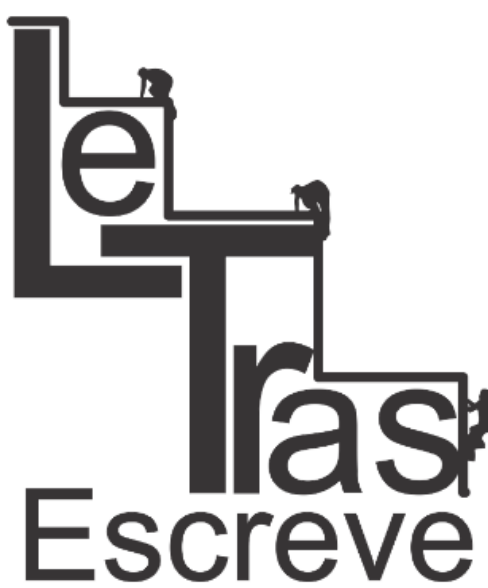

(ISSN 2238-8060) ação todo(s)/tudo é recorrente na fala de moradores de comunidades afrodescendentes isoladas, compostas em sua maioria por descendentes de escravos africanos e de antigos quilombolas, cuja gramática é aqui denominada pelo termo geral português afro-brasileiro (PAB). Tal variação também ocorre no português brasileiro popular e no português brasileiro culto falado.

O objetivo deste artigo é descrever e analisar os aspectos sintáticos do quantificador tudo nos dialetos afro-brasileiros, comparando-os com a gramática do $\mathrm{PB}$, baseado na teoria de Princípios e Parâmetros (CHOMSKY, 1995, e obras subsequentes). Essa perspectiva tem como objetivo a descrição e explicação dos dados linguísticos do ponto de vista mentalista, ou seja, a língua-interna, apesar de, por questões de limitação de acesso aos dados, trabalhemos com dados de produção da língua-externa, acompanhados de juízos de aceitabilidade.

Já existe uma literatura consolidada sobre os quantificadores flutuantes nessa abordagem teórica. Há duas principais linhas de análise. Numa, o quantificador é gerado numa posição argumental, junto com o DP/NP que modifica, e esse elemento se move, deixando o quantificador "encalhado" (stranded) na sua posição de base (SPORTICHE, 1988). Na outra abordagem, o quantificador seria sempre um elemento adverbial, gerado diretamente na posição em que ocorre (cf. BOBALIK, 1995). Há também abordagens mistas (cf. FITZPATRICK, 2006). Neste trabalho, considerarei uma abordagem mista, em que a palavra tudo corresponde a dois itens lexicais: com valor de intensificador, é um elemento adjunto, pois modifica o evento inteiro, enquanto tudo com valor de quantificador seria gerado numa posição argumental, como núcleo de um Q(uantificador) acima de um DP. Isso dito, nada impede que a representação em que um QP, acompa-

https://periodicos.unifap.br/index.php/letras

Macapá, v. 7, n. 2, 20 semestre, 2017. 
nhado de um DP, ocorra em posição adjunta, como em Eu trabalho todos os dias.

Há cerca de dez anos, muitos estudos vêm discutindo a flutuação da palavra tudo, que não apresenta concordância com o nome que o acompanha, no PB. Os estudos gerativistas não têm distinguido variantes dialetais, tratando todos os falantes do PB como portadores da mesma gramática internalizada. No entanto, há divergências entre os dados apresentados, como se observa na seguinte citação de um gramático tradicional:

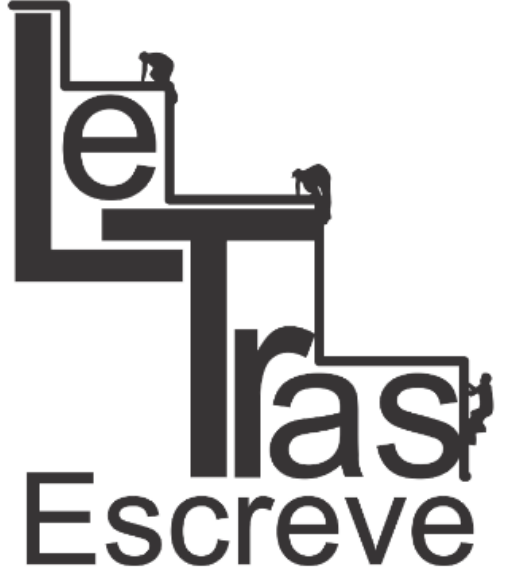

(ISSN 2238-8060)

"As crianças chegaram aqui tudo sujas" - Na língua falada popular há esse vício: dizer tudo no lugar de todo; tuda, no lugar de toda; tudas, no lugar de todas etc. Consertemos, principalmente se tratando da língua escrita: Os bichinhos morreram todos. (E não: tudo). (SACCONI, 1990, p. 83.)

Essa observação demonstra ser preciso olhar com mais cuidado para os fatos do português brasileiro popular (PBP), contrastandoos com aqueles dados do português brasileiro culto falado (PBCF). Entende-se por PBP uma supravariedade que inclui falantes de áreas urbanas, sem acesso à educação formal ou que não concluíram o ensino superior. O PBCF, por sua vez, se manifesta na fala de pessoas com nível superior completo e, por isso, mais influenciadas pela norma padrão.

Considerando que alguns fenômenos do PB têm sido atribuídos à influência de línguas africanas de substrato, enfatizo, neste estudo, os dados de variedades de português afro-brasileiro, que também apresentam a variação entre tudo e todo(s) (cf. LUCCHESI; BAXTER; RIBEIRO, 2009). Além disso, relaciono-os aos dados do PBP e do PBCF colhidos por meio de juízos de aceitabilidade junto a falantes com essas características sociolinguísticas (TRANNIN, 2016). Essa i- 


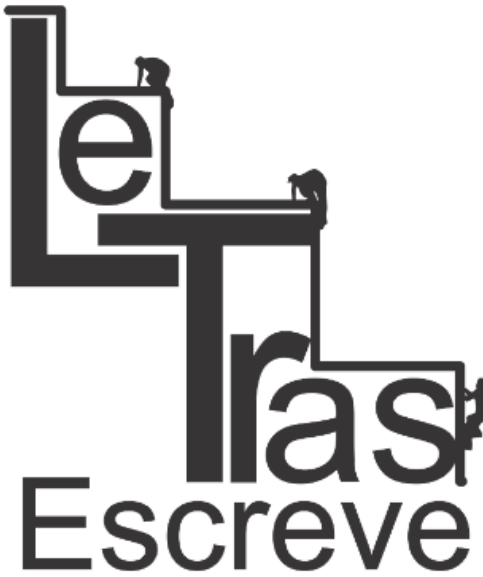

(ISSN 2238-8060)

deia associa uma maior flutuação de tudo nas variedades sem concordância a uma distribuição mais ampla do item todo(s), o que parece derivar da perda da morfologia de concordância, um efeito do contato linguístico. Em outras palavras, a hipótese central do estudo é a de que há uma correspondência diretamente proporcional entre a quantidade de contextos em que o tudo ocorre (no lugar de to$d o(s))$ e os contextos em que flutua, o que se explica por propriedades distintas, que podem ser traduzidas na existência de duas gramáticas distintas na comunidade de fala.

Este trabalho está organizado como segue. Na seção 2, discuto as propostas existentes na literatura do PB (englobando dados do PBP e do PBCF) a respeito da palavra tudo. Na seção 3, detalho os dados obtidos a partir de quatro trabalhos descritivos sobre comunidades caracterizadas como falantes do PAB. Na seção 4, apresento minha análise para a derivação de tudo em duas gramáticas. Na seção 5, discuto como o PAB se situa com relação a tais gramáticas. Finalmente, na seção 6, apresento as considerações finais do trabalho.

\section{As gramáticas de tudo no português brasileiro}

Nesta seção, faço um comentário sobre as análises a respeito de tudo no PB, que se centram sobre a variedade culta, isto é, o PBCF. Ao final, apontarei evidências de julgamentos díspares para a gramática do PBP.

Trabalhos como Godoy (2005) e Godoy; Cançado (2006) observaram que a construção [tudo DP] é agramatical tanto na posição de sujeito, em (1a), quanto na de objeto, em (1b). A ordem [DP tudo], porém, é gramatical, como visto em (2): 
(1) a. * Tudo as coisa é cara.

b. *Meu irmão comeu tudo os pão.

(2) a. Os aluno tudo reprovaram na prova.

b. Meu pai pintou o portão tudo.

A posição pós-verbal do quantificador é gramatical com verbos de ligação e inacusativos, como em (3) (exemplos de GODOY, 2005, p. 31-32), mas não são tranquilamente aceitáveis com outros verbos inergativos e transitivos, como em (4) (exemplos de GODOY, 2005, p. $31 ; 28)$ :

(3) a. Os cara foram tudo covarde.

b. Os menino chegou tudo.

(4) a. ?Os menino correu tudo.

b. ?Os menino comeram tudo o bolo.

Nessa gramática, tudo também pode ter uma função de intensificador, como ilustrado abaixo (exemplo de Trannin, 2016, testado com informantes de PB):

(ISSN 2238-8060)

(5) Minha mãe xingou tudo o guarda.

A interpretação em (5) não é a de que a mãe xingou o guarda inteiro, mas sim que xingou muito o guarda. Nesse caso, tudo pósverbal se comporta como um intensificador do verbo e tem o sentido de muito, completamente (PIRES DE OLIVEIRA, 2003).

Esse quadro parece resumir bem os possíveis usos do elemento tudo no PBCF. De maneira interessante, os juízos de Lacerda (2012, p. 52) e Cruz (2016, p. 27) com respeito à distinção entre clas- 
ses verbais - cf. (3) e (4) - não são as mesmas apresentadas acima: ${ }^{3}$

(6) a. Os meninos gritaram tudo animado.

b. Os alunos fizeram tudo a prova.

Sugiro que esses exemplos seriam casos de uma gramática distinta, em que tudo tem maior liberalidade de contextos de uso, sendo possível até mesmo o tudo pré-nominal. Essa conclusão deriva dos exemplos a seguir, extraídos da internet, e de juízos de aceitabilidade colhidos junto a falantes com perfil sociolinguístico característico do PBP, que são respectivamente semelhantes a (1a); e (4b) / (5b):

tudo os cigarro que eu compro só fala sobre impotência sexual eu to começando a ficar ofendido. ${ }^{4}$

(8) Nossa, que gritaria. As crianças perderam tudo a esperança agora. $^{5}$

Apesar dessas distinções entre as variedades do PB, nota-se que, quanto ao uso de tudo associado a nome nu (sem artigo defini(ISSN 2238-8060) do), há uma semelhança:

(9) Manifestante é tudo vagabundo. ${ }^{6}$

Entretanto, chama a atenção uma distinção básica entre a distribuição de todo(s) e de tudo nesse contexto, pois a flutuação do

\footnotetext{
${ }^{3}$ Agradeço a um dos pareceristas por ter sugerido esse último exemplo. Vale notar, no entanto, que o predicado secundário pode modificar os juízos de aceitabilidade, pois também é possível interpretar a sentença com tudo animado como um constituinte com valor apositivo.

${ }^{4}$ https://twitter.com/liuizzz/status/267260762098110464

${ }^{5}$ https://twitter.com/CalcinhasNoBox/status/500833059676360704

${ }^{6}$ https://twitter.com/The__Stranger/status/345333623874011136

https://periodicos.unifap.br/index.php/letras

Macapá, v. 7, n. 2, 2ㅇs semestre, 2017.
} 
primeiro depende da existência de um determinante:

(10) *Homem é todo mortal.

Nos contextos restantes, a distribuição de todo(s) e tudo, considerando o PBP, não seria diferente. Já com relação ao PBCF, haveria uma série de distinções, já mencionadas.

Dessa apresentação, ainda ocorre o uso de tudo como quantificador universal, não relacionado a um DP, que será denominado de tudo pronominal. Nesse caso, igualmente não há diferença entre variedades do PB, mas o há entre todo(s) e tudo. Deixarei a discussão teórica sobre a possibilidade de analisar esse item como estando sozinho no sintagma QP ou com um DP nulo para depois.

Os dados apresentados acima demonstram que há mais de uma gramática sendo discutida nos trabalhos sobre o PB. Para meIhor entender o espectro dessa variação, incluo a seguir uma apresentação de variedades do PAB, a fim de verificar se elas são homogêneas quanto à distribuição de tudo e todo(s).

\section{As gramáticas de tudo no português afro-brasileiro}

Nas próximas seções, descrevo as propriedades sintáticas do tudo nas variedades afro-brasileiras, com base na fala de moradores de quatro comunidades quilombolas: Furnas de Boa Sorte (MS), MiIho Verde (MG), Bom Despacho (MG), Jurussaca (PA). Os dados referentes à comunidade afro-brasileira de Mato Grosso do Sul foram coletados a partir de narrativas de informantes entrevistados pelo pesquisador João Batista de Andrade Filho ${ }^{7}$. Os dados das outras três

\footnotetext{
${ }^{7}$ Agradeço ao pesquisador João Batista de Andrade Filho por ter cedido as transcrições
} 


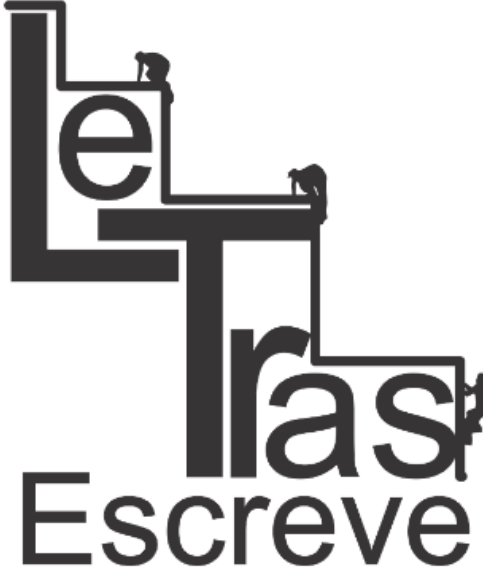

(ISSN 2238-8060)

comunidades foram coletados de transcrições de entrevistas realizadas pelos pesquisadores do Projeto Levantamento etnolinguístico de comunidades afro-brasileiras de Minas Gerais e Pará (PETTER; OLIVEIRA, 2011).

As sentenças foram classificadas de acordo com o tipo de construção em que tudo ocorre e a sua posição na oração, e comparadas com a distribuição do quantificador todo(s). ${ }^{8} \mathrm{~A}$ base de comparação é a distribuição apontada para o PBCF, resumida na seção anterior, e a expectativa é que o português afro-brasileiro apresente uma distribuição semelhante aos dados do PBP, isto é, os itens tudo e todo(s) podem variar em todos os contextos sintáticos possíveis. Algumas informações sócio-históricas sobre tais comunidades são oferecidas para dar uma ideia sobre o grau de isolamento de cada uma delas.

\subsection{Comunidade de Furnas de Boa Sorte (MS)}

Furnas de Boa Sorte é composta por 150 pessoas de 36 famílias remanescentes do quilombo, situada no município de Corguinho, região central de Mato Grosso do Sul. A comunidade, fundada por escravos fugidos na década de 80 do século XIX, tornou-se um local de isolamento devido à posição geográfica, em virtude da conformação sinuosa do terreno que compõe a Serra de Maracaju (ANDRADE FILHO, 2007).

Como se observa nos dados abaixo, o item tudo pode ter valor pronominal, como em (11); pode estar associado a um DP, com o quantificador preposto (12), e posposto (13); construções flutuantes, com tudo na posição pós-verbal, associado a um DP com função de

\footnotetext{
das entrevistas para esta pesquisa.

${ }^{8}$ Esse elemento nem sempre funciona como quantificador universal, como bem observou Pires de Oliveira (2003). Agradeço a um parecerista anônimo por ter me chamado a atenção para esse fato.
}

https://periodicos.unifap.br/index.php/letras

Macapá, v. 7, n. 2, 2ㅇs semestre, 2017. 
sujeito da oração, em (14a,b):

(11) I já dechô tudo arrumadu...

(12) Agora tudo as coisa é caru...

(13) Dexo os fi tudo criado graças a Deus...

(14) a. A fiarada isparramô tudu...

b. Intão teu ispíritu tá tudo ai in redó dela ai né...

Já o item todo(s) apresenta uma única ocorrência do quantificador singular associado a um DP, em (15). ${ }^{9}$ Com nomes nus, só foram encontradas ocorrências de todo na expressão "todo mundo", em (16):

(15) Trabalhava o dia todu

(16) Todu mundu foi imbora...

\subsection{Comunidade de Milho Verde (MG)}

Milho Verde é um distrito da cidade de Serro, localizado na porção central da Serra do Espinhaço, à margem da Estrada Real. A comunidade, situada na região do Alto Jequitinhonha, foi um dos primeiros povoados do território mineiro, nos primórdios da exploração de pedras preciosas do Distrito Diamantino. A população de cerca de 1.000 habitantes é constituída por remanescentes de quilombos e se divide entre o perímetro urbano e os bairros rurais de Baú, Ausente e Barra da Cega (ANDRADE, 2013).

A palavra tudo aparece nos seguintes contextos. A maioria são casos em que ele tem valor pronominal, como em (17). Também há

\footnotetext{
${ }^{9}$ Da mesma forma que em estudos diacrônicos, dada a dificuldade de verificar os juízos de aceitabilidade junto aos falantes, considero que essa ocorrência é suficiente para atestar a variação entre tudo e todo(s).
} 
exemplos de tudo associado a DP, na configuração [DP tudo], tanto na posição de sujeito, em (18a), como na posição de objeto, em (18b), e também de tudo associado a nome nu, tanto pré-nominal (19a) quanto pós-nominal (19b). Foram registrados ainda casos de tudo na posição pós-verbal, associado a um sintagma nominal [+humano] na posição de sujeito da sentença, em (20a,b), um exemplo de intensificador, em (21): ${ }^{10}$

(17) A lavadêra de roupa veio pra tudo lavá é.

(18) a. Essas [terra] tudo vem na cabeça, ó

b. Deus já fez os trem tudo.

(19) a. ieu fui, ieu fui um grande líder de tudo momento lá dentro

b. eu entendo de raça tudo

(20) a. os defuntos hoje já saem tudo dentro de carro

b. os defuntos tão tudo rico

(21) nós chegava da escola tudo moiado

Os exemplos de ocorrências com o quantificador todo(s) são dados abaixo. Em (22), há um caso de todo(s) com valor pronominal; (ISSN 2238-8060) em (23), associado a DP, na configuração [DP tudo]; em (24), todo é associado a nome nu; em (25) e (26), todo tem valor de intensificador:

(22) São parente é, ... e no vissungo todos são meu parente.

(23) (...) passava essa estrada toda aqui ó...

(24) trabalhador muito bom que ele era, ...fazia todo serviço que precisasse fazer.

\footnotetext{
${ }^{10}$ Os dados foram transcritos tal como nos arquivos a que tive acesso, havendo, portanto, variação ortográfica entre todo e todu, que não implica pronúncia diferente na maior parte do país.
}

https://periodicos.unifap.br/index.php/letras

Macapá, v. 7, n. 2, 20 semestre, 2017. 
(25) ele ficava todo assim sem olha po... povo

(26) Ela toda [aguentiada] ne... e... enxugô o pé dele.

\subsection{Comunidade de Bom Despacho (MG)}

Bom Despacho está localizada na região centro-oeste do Estado de Minas Gerais, a 147 km de Belo Horizonte, e possui 45.626 habitantes (de acordo com dados do IBGE, censo 2010). A grande concentração de população africana em terras mineiras visava à exploração de ouro e diamante e à produção de cana-de-açúcar. A presença africana é atestada pelos quilombos que existiram, pelas tradições religiosas de origem africana e pela atestação da chamada "língua do negro da Costa" (QUEIROZ, 1993).

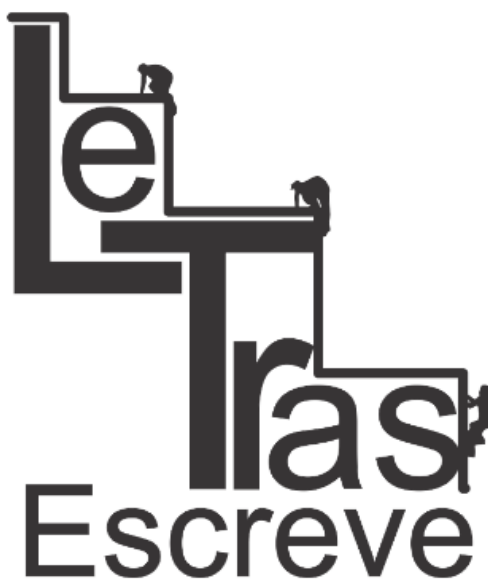

(ISSN 2238-8060)

A maioria das ocorrências de tudo nessa comunidade tem valor pronominal, como em (27). Foram registrados também casos de tudo associado a DP, na ordem [DP tudo], em (28); tudo associado ao DP sujeito em posição pós-verbal, em (29), e alguns casos em que tudo parece funcionar como um advérbio, em (30):

(27) E quem pegá a cartilha pode lê, pode aprendê tudo nela aí ó...

(28) a. Ó... ele tá com... c'os badalo tudo doeno...

b. os homi tudo olha... sabe que é as perna...

(29) a. ... as ocaia tá tudo bom...

b. ...os canambora tava viajando tudo...

(30) Eles ficaro tudo curioso...

As ocorrências das formas todo(s) são exemplificadas a seguir. Em (31) há um caso de elemento com valor pronominal; em (32a,b), todo(s) está associado a DP, em posição pré ou pós-nominal. Em (33), o elemento está associado a um nome nu; em (34), tem uma leitura 
possível com valor de intensificador:

(31) É... reparte demais pra escola todos aqui...

(32) a. E o...o ritmo deles é [...] completamente diferente de todos os ritmos.

b. Tá entregando o ouro todinho.

(33) É ói, vô querê todo caxa ingura.

(34) tu... já tá toda arrumadinha...

\subsection{Comunidade de Jurussaca (PA)}

Jurussaca está localizada a aproximadamente $10 \mathrm{~km}$ da cidade

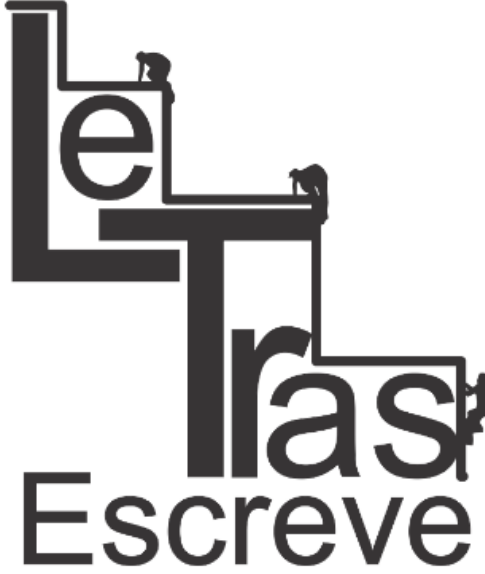

(ISSN 2238-8060) de Tracuateua e a $25 \mathrm{~km}$ da cidade de Bragança, a nordeste do estado do Pará, norte do Brasil. Segundo moradores, a comunidade teria surgido a partir de quatro escravos que, fugidos do Maranhão, se instalaram na região (OLIVEIRA; FERNANDES, 2010). A população oscila entre 500 e 600 pessoas, constituindo cerca de 80 a 90 famílias (SILVA, 2014, p. 11).

Nos dados dessa comunidade, são frequentes as ocorrências de tudo pronominal, como em (35). Foram registrados também casos de tudo associado a DP na ordem [Q DP], em (36a), e na ordem [DP Q], em (36b); tudo associado a nome nu, em (37), e em construções com flutuação, em (38). Em alguns casos, tudo tem valor de intensificador, como em (39):

(35) Tinha que comprá tudo.

(36) a. Ás vez [ele] batiza tudinho os menino.

b. [...] e vim, dancei, o vento me levava pá qualquê lado c'as pessoa tudo... ...vem gente de Bragança, de Tracuateua, de tudo lugar aí pra 
ele benze, pá ele...

...os rancho era tudo por debaixo dos mato

(39) A ... a família ali do... do [Gas]... era tudo bonito o olho...

As ocorrências do elemento todo(s) em Jurussaca são ilustradas a seguir. Em (40) encontram-se elementos com valor pronominal. Em (41), associado a DP em posição pré-nominal; em (42), associado a DP, pós-nominal; em (43), associado a nome nu; em (44), com valor de intensificador:

(40) Todas... todas vão pro hospital... todas.

(41) Até é... ia mais além, né, alfabetizava e levava também com todas as série, tinha que trabalhá de primêra até a tercêra série...

(42) A gente enxergava as janela todinha do cara... dos cara...

(43) É...é toda carne aí, eles vende, é...ele sabe cortá muito bem [...]

(44) até roê, aí passô oito anos ele aí, todo teimoso

A seguir, ofereço uma comparação dos dados dessa comuni(ISSN 2238-8060) dade com as arroladas nas seções anteriores.

\subsection{Quantificação e discussão dos dados}

A distribuição das ocorrências do quantificador tudo na fala das comunidades quilombolas analisadas é apresentada na Tabela 1 a seguir. Noto que, apesar de teoricamente as categorias [Tudo DP], [DP tudo] e [Tudo flutuante] compartilharem a mesma estrutura de base, elas serão apresentadas em separado, mantendo assim a distinção entre o nível observacional e o nível explicativo. 
Tabela 1 - Distribuição de tudo em variedades do PAB.

\begin{tabular}{|c|c|c|c|c|c|c|c|c|}
\hline & \multicolumn{2}{|c|}{ F. B. Sorte } & \multicolumn{2}{|c|}{ Milho Verde } & \multicolumn{2}{|c|}{ B. Despacho } & \multicolumn{2}{|c|}{ Jurussaca } \\
\hline & $\mathrm{n}$. & $\%$ & $\mathrm{n}$. & $\%$ & $\mathrm{n}$. & $\%$ & n. & $\%$ \\
\hline $\begin{array}{l}\text { Tudo prono- } \\
\text { minal }\end{array}$ & 9 & 33.3 & 47 & 69.1 & 44 & 74.6 & 109 & 73.2 \\
\hline Tudo DP & 3 & 11.2 & & & & & 5 & 3.4 \\
\hline DP tudo & 5 & 18.5 & 8 & 11.8 & 6 & 10.2 & 9 & 6 \\
\hline $\begin{array}{l}\text { Tudo flutuan- } \\
\text { te }\end{array}$ & 9 & 33.3 & 10 & 14.7 & 8 & 13.5 & 23 & 15.4 \\
\hline Tudo N & & - & 2 & 2.9 & & - & 2 & 1.3 \\
\hline $\begin{array}{l}\text { Tudo intensi- } \\
\text { ficador }\end{array}$ & 1 & 3.7 & 1 & 1.5 & 1 & 1.7 & 1 & 0.7 \\
\hline Total & 27 & 100 & 68 & 100 & 59 & 100 & 149 & 100 \\
\hline
\end{tabular}

As ocorrências de tudo pronominal são predominantes na fala das comunidades afro-brasileiras. A exceção é o dialeto de Furnas de Boa Sorte, em que tudo pronominal tem a mesma proporção de tudo em construções flutuantes. Na maior parte das ocorrências de tudo pronominal, ele apresenta traço semântico [-humano], mas há registro desse elemento com antecedente animado, especialmente na comunidade de Jurussaca, com 13 ocorrências em 109 casos.

Os casos de tudo intensificador são raros, assim como tudo associado a nomes nus, que só aparece em Milho Verde e Jurussaca. Já as construções com tudo associado a um sintagma com determinante (ISSN 2238-8060) na ordem [Q DP] só aparecem em Jurussaca e Furnas de Boa Sorte, mas as sentenças com o quantificador posposto estão presentes em todas as comunidades.

Já a distribuição do quantificador todo(s) nas quatro comunidades é apresentada resumidamente na Tabela 2 abaixo. 
Tabela 2 - Distribuição de todo(s) em variedades do PAB.

\begin{tabular}{|c|c|c|c|c|c|c|c|c|}
\hline & \multicolumn{2}{|c|}{ F. B. Sorte } & \multicolumn{2}{|c|}{ Milho Verde } & \multicolumn{2}{|c|}{ B. Despacho } & \multicolumn{2}{|c|}{ Jurussaca } \\
\hline & n. & $\%$ & n. & $\%$ & n. & $\%$ & n. & $\%$ \\
\hline Todo(s) & & - & 5 & 11.4 & 1 & 2 & 19 & 10.7 \\
\hline Todo(s) DP & & - & 3 & 6.8 & 3 & 6.2 & 52 & 29.2 \\
\hline DP todo & 1 & 16.7 & 4 & 9.1 & 4 & 8.2 & 25 & 14 \\
\hline $\begin{array}{l}\text { Todo(s) flutu- } \\
\text { ante }\end{array}$ & & -- & 4 & 9.1 & & --- & 1 & 0.6 \\
\hline Todo N & 5 & 83.3 & 25 & 56.8 & 40 & 81.6 & 72 & 40.4 \\
\hline $\begin{array}{l}\text { Todo } \\
\text { intensificador }\end{array}$ & & -- & 3 & 6.8 & 1 & 2 & 9 & 5.1 \\
\hline Total & 6 & 100 & 44 & 100 & 49 & 100 & 178 & 100 \\
\hline
\end{tabular}

Da tabela acima, chama a atenção a distribuição do quantificador todo(s) em Furnas de Boa Sorte, em que a ocorrência predominante é a construção com nomes nus. Nas outras três comunidades, os casos de todo(s) associado a nomes nus é a ocorrência mais frequente, em parte pela presença da expressão "todo mundo": 11 ocorrências em 25 (Milho Verde), 20 ocorrências em 40 (Bom Despacho) e 28 ocorrências em 72 (Jurussaca). As construções flutuantes foram mais comuns na comunidade de Milho Verde, enquanto o quantificador com valor de intensificador foi mais frequente em Jurussaca.

Apesar da disparidade de dados referentes ao uso e do fato de em algumas comunidades não ocorrerem alguns dos tipos de quantificadores mencionados, a expectativa de que o elemento tudo compartilha nessas comunidades uma distribuição mais ampla que no PBCF foi confirmada em parte. Em suma, nas comunidades próximas a grandes zonas urbanas, como Milho Verde e Bom Despacho, a distribuição é semelhante ao PBCF; nas comunidades mais isoladas, como Furnas de Boa Sorte e Jurussaca, a distribuição de tudo é mais ampla, aproximando-se do PBP.

Antes de especificar as razões para essa divergência entre as variedades do $\mathrm{PAB}$, detalho a seguir a proposta de análise para as 
duas gramáticas de tudo no PB.

\section{As duas gramáticas de tudo}

A proposta de análise a seguir baseia-se na identificação e descrição de duas gramáticas para o quantificador tudo no PB, uma restritiva e a outra, radical.

\subsection{A gramática restritiva}

Começo a apresentação pela gramática restritiva, que seria representativa do PBCF. Esse termo foi escolhido pois nela o quantificador tudo tem distribuição mais restrita face a todo(s), como observaram Godoy (2005), Godoy; Cançado (2006) e Vicente (2006), entre outros.

Em síntese, na gramática restritiva, tudo é um quantificador adnominal que pode ocupar a posição pós-nominal e que pode flutuar em alguns contextos; pode funcionar também como um modificador de evento aparecendo em posição pós-verbal. Adaptando a análise de Sedrins (2011), assumo que, na ordem [DP Q], tudo seleciona uma categoria vazia PRO, relacionada ao antecedente por controle (cf. Chomsky, 1981), como na estrutura a seguir: ${ }^{11}$

(45) [DP [DP Os aluno] [QP tudo [PRO]]

A presença de PRO explicaria a não-aceitação de sentenças como (46):

(46) ?Os menino correu tudo.

\footnotetext{
${ }^{11}$ Indico o leitor interessado nos detalhes dessa análise a consultar Trannin (2016, p. 174175).
} 
Esse fato seria explicado pela teoria de fases (CHOMSKY, 2008). Com verbos inergativos, PRO não pode ser controlado pelo sujeito porque vP é uma fase forte, que bloqueia o controle. Tudo é permitido em posição pós-verbal em sentenças com verbos de ligação como ser e estar e com verbos inergativos porque, nesses casos, não há uma projeção vP que bloqueie o controle de PRO pelo sujeito:

(47) a. *[TP [DP as menina $]_{\mathrm{i}}$ dançou $_{\mathrm{j}}\left[\mathrm{vvP}_{\mathrm{vP}}\left[\mathrm{t}_{\mathrm{i}}[\mathrm{QP}\right.\right.$ tudo [PRO $\left.\left.\left.]\right] \mathrm{t}_{\mathrm{j}}\right]\right]$

b. [TP [DP As empregadas $]_{i} t_{a} o_{j}\left[_{v p} t_{i}\left[_{Q P}\right.\right.$ tudo [PRO]] $t_{j}[p P$ de folga]]].

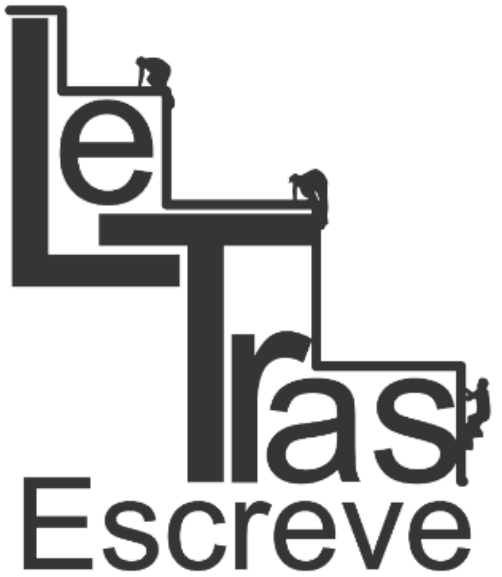

(ISSN 2238-8060)

Como já mencionado, quando se comporta como um intensificador, tudo está adjungido ao vP, como na estrutura abaixo:

(48) [TP [DP minha mãe $]_{j} \operatorname{xingou}_{i}\left[{ }_{v P}\left[Q P\right.\right.$ tudo] ${ }_{v p P} t_{j}\left[{ }_{v P} t_{i}[D P\right.$ o guarda]]]]]

Essa proposta se baseia na semântica da quantificação de Pires de Oliveira (2003), para quem a mesma interpretação não se aplica à chamada "quantificação de determinante" e à "quantificação adverbial". ${ }^{12}$ De maneira crucial, entende-se que o elemento tudo em (48) inclui um operador genérico, já que, em frases com um sujeito coletivo ou plural que é argumento de um predicado nominal, não é obrigatória a interpretação de que o quantificador se aplica a todos os referentes do conjunto em questão ((49a) foi retirado de Pires de Oliveira 2003, p. 203):

\footnotetext{
${ }^{12}$ No entanto, cf. Vicente; Gomes (2013) para um tratamento unificado a esses dois itens.
} 

(49)
a. A criançada tá toda feliz.
b. Os menino tá tudo feliz

A concordância entre toda e a criançada em (49a) pode implicar a existência de um PRO junto ao elemento todo(s), que, no entanto, inexiste no caso de tudo em (48). Evidentemente, um detalhamento da relação entre a semântica e a sintaxe dessas construções demandaria mais espaço e fugiria do objetivo deste artigo. ${ }^{13}$

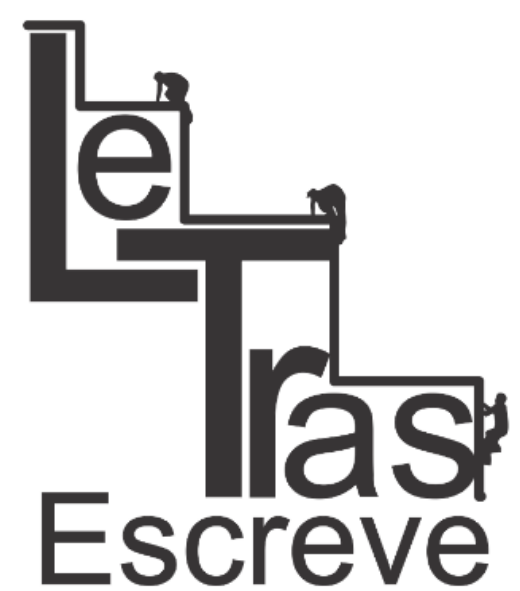

(ISSN 2238-8060)

\subsection{A gramática radical}

A gramática "radical" é assim denominada porque nela a distribuição de tudo e de todo(s) parece ser semelhante. Em suma, os dois elementos parecem ter propriedades sintáticas similares, ainda que divirjam em suas características morfológicas (especialmente a possibilidade de concordância no primeiro elemento). Dessa forma, a quantidade de contextos onde ocorre tudo é bastante ampla:

(50) a. Tudo as coisa é cara.

b. Meu irmão comeu tudo os pão.
a. Os lixeiro tudo tá em greve.
b. Meu vizinho quebrou os portão tudo.

A ordem pós-verbal é gramatical tanto com verbos de ligação e inacusativos, em (52), quanto com verbos inergativos e transitivos, em (53):

\footnotetext{
${ }^{13} \mathrm{Um}$ aspecto igualmente intrigante tem a ver com a possibilidade de concordância entre tudo e o DP sujeito, em dados da internet, da mesma forma que todo(s), o que pode ser visto como efeito de hipercorreção ou como uma terceira gramática. Deixo essa discussão para trabalho futuro.
}

https://periodicos.unifap.br/index.php/letras

Macapá, v. 7, n. 2, 2ㅇsemestre, 2017. 
(52) a. Os lixeiro tá tudo em greve.

b. Os vizinho chegou tudo.

(53) a. As menina viajaram tudo.

b. Os menino comeu tudo o bolo.

Nessa gramática, portanto, tudo é um quantificador adnominal sem restrições quanto à posição e que pode flutuar junto a diferentes tipos de predicados. Além disso, também se comporta como um modificador de evento.

Nesse caso, tudo seleciona um DP. Na ordem [Q DP], tudo é um núcleo que seleciona um complemento lexical, e não um pronome nulo como na gramática restritiva (cf. Vicente, 2006). Isso é ilus-

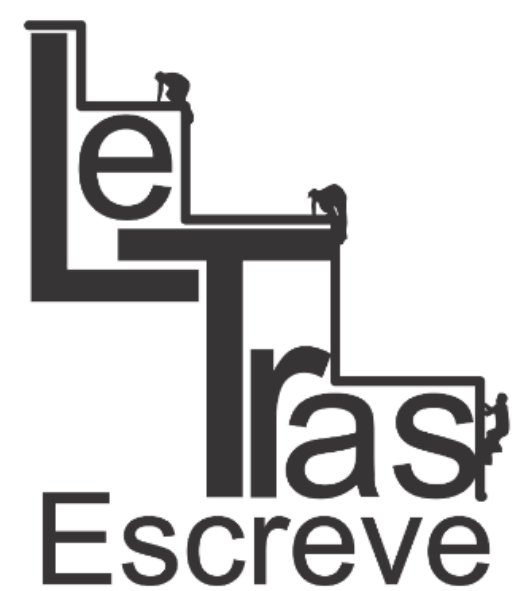

(ISSN 2238-8060)

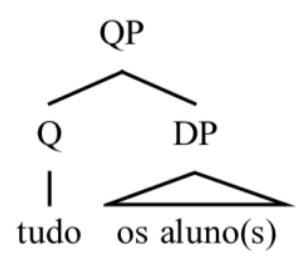

Adaptando a proposta de Lacerda (2012) para todo(s), assumo que o quantificador projeta uma camada informacional de foco, que está relacionada à derivação da ordem [DP Q] e à flutuação. Se o quantificador for selecionado do léxico sem um traço de foco, os elementos permanecem na posição em que são gerados. Se o quantificador possuir um traço de foco, o sintagma nominal deve se mover obrigatoriamente para [Spec,FocP], derivando a ordem [DP Q], como na seguinte representação do sintagma os aluno(s) tudo:

https://periodicos.unifap.br/index.php/letras Macapá, v. 7, n. 2, 2ㅇ semestre, 2017. 


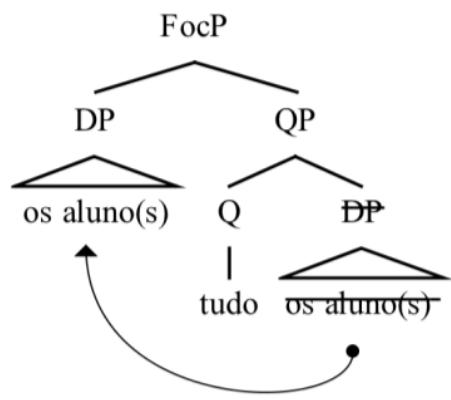

Após esse movimento interno à projeção nominal, o DP pode se mover para uma projeção mais alta, $\mathrm{Spec}, \mathrm{qP}$, deixando o quantificador encalhado:

(56) [tp [dp Os aluno $]_{i}$ viajaroj $\left[\right.$ [vP [qP [Focp $\left.\mathrm{t}_{\mathrm{i}}\right]\left[\mathrm{QP}\right.$ tudo $\left.\left.\left.\left.\mathrm{t}_{\mathrm{j}}\right]\right] \mathrm{t}_{\mathrm{j}}\right]\right]$

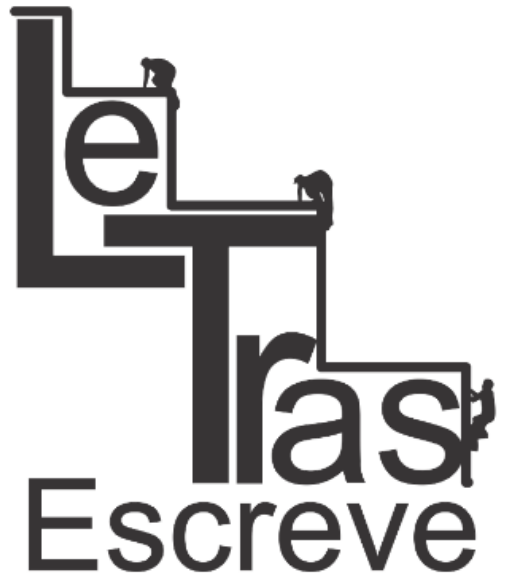

(ISSN 2238-8060)

\section{A sintaxe de tudo em variedades do português afro-brasileiro}

A análise da sintaxe de tudo nas variedades afro-brasileiras estudadas interage com a expressão da concordância nominal e verbal, pois se relaciona com a distinção entre dialetos de morfologia rica, em que tudo é restrito a poucos contextos, e os dialetos com morfologia pobre, em que tudo ocorre em todos os contextos em que se espera todo(s) no português padrão, sendo praticamente o único quantificador disponível.

Nos dialetos das comunidades mineiras de Bom Despacho e

\footnotetext{
${ }^{14}$ Para um tratamento unificado desses dois itens, cf. Vicente; Gomes (2013).
} 
Milho Verde, que apresentam variação no número e na flexão de verbo, o quantificador tudo aparece em apenas alguns contextos, na posição pós-nominal e pós-verbal:

(57) os homi tudo olha... sabe que é as perna...(Bom Despacho, MG)

(58) os defuntos tão tudo rico (Milho Verde, MG)

Nesses dialetos, a sintaxe de tudo é semelhante à da gramática restritiva: o quantificador é modificador adjungido ao nome e tem como complemento uma categoria vazia. A estrutura do sintagma relevante em (57) é dada em (59):

(59) [TP [DP [DP Os homi] [QP tudo [PRO]] $]_{i}$ olha $\left._{j}\left[{ }_{v P} t_{i} t_{j}\right]\right]$

No caso da sentença predicativa com verbo de ligação, em (58), o DP se move para ocupar a posição de sujeito e o quantificador fica na posição em que é gerado, como na estrutura abaixo:

(60) [TP [DP os defuntos $]_{i}$ tão ${ }_{j}\left[v P t_{j}\left[s c\right.\right.$ [DP $t_{i}[Q P$ tudo [PRO]]] [Adjp rico] ]]]

A relação entre o quantificador e o associado nominal é dada por controle de PRO, assim como na gramática restritiva do elemento tudo.

Já os dialetos falados em Jurussaca (PA) e em Furnas de Boa Sorte (MS) apresentam morfologia pobre e tudo ocupa os mesmos contextos do quantificador todo(s): 
(61)
a. vendeu tudo as madeira... (Jurussaca, PA)
b. essas estrada tudo era caminho do inferno.

(62) a. Agora tudo as coisa é caru... (Furnas de Boa Sorte, MS)

b. A fiarada isparramô tudu...

A sintaxe de tudo nesses dialetos é a mesma encontrada na gramática radical. Tudo é um quantificador que seleciona um sintagma nominal (com ou sem determinante). Desta forma, o quantificador pode aparecer tanto na ordem [Q DP], em (63), quanto na ordem [DP Q], por movimento do associado nominal, em (64):

(63) vendeu [qp [Focp [op tudo [Dp as madeira]]]].

(64) [qp [Dp essas estrada $]_{i}\left[\right.$ [Focp $\left.t u d o_{j}\left[{ }_{Q p p} t_{i} t_{j}\right]\right]$ era caminho do inferno.

Em construções flutuantes como as de (62b), o quantificador fica encalhado quando o associado nominal se move para posições mais altas, como já visto no exemplo (55).

Há dois pontos interessantes nesses dialetos. Na fala de Jurus(ISSN 2238-8060) saca, a ocorrência de tudo é superior à de todo(s) em algumas construções, como o quantificador sozinho e na posição pós-verbal (flutuante). Já na comunidade sul-mato-grossense, tudo é o quantificador predominante.

\section{Considerações finais}

Neste artigo, analisei dados provenientes de comunidades quilombolas, representativas do $\mathrm{PAB}$, referentes à gramática do elemento tudo, e relacionei-os a diferenças dialetais presentes no próprio 


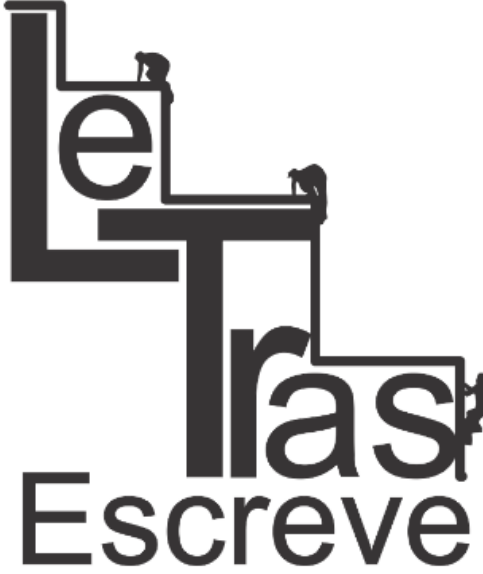

(ISSN 2238-8060)
PB. Assim, propus duas gramáticas para o elemento tudo: a gramática restritiva estaria presente no PBCF, enquanto a gramática radical seria encontrada no PBP.

Nos dados das comunidades quilombolas em estudo é possível observar uma distinção quanto à realização de tudo nos contextos sintáticos de uso. Aparentemente, nas comunidades de Milho Verde (MG) e de Bom Despacho (MG), tudo é usado como variante do quantificador todo como intensificador e em contextos de flutuação. Já na fala dos moradores de Jurussaca (PA) e em Furnas de Boa Sorte (MS), tudo ocorre nos mesmos contextos de todo. Pode-se dizer, portanto, que nas comunidades Bom Despacho e Milho Verde, a gramática de tudo se aproxima da gramática restritiva, enquanto Jurussaca e Furnas de Boa Sorte apresentam a gramática radical.

Um ponto que poderia ser mais bem trabalhado no futuro é a presença dos itens lexicais tudo e todo(s) em variação. Nesse aspecto, aparentemente Furnas de Boa Sorte estaria em processo de mudança mais avançada, pois cinco das seis ocorrências do elemento todo referem-se à expressão cristalizada todo mundo, havendo apenas um caso do quantificador associado a um DP em o dia todo, que também se caracteriza como expressão cristalizada. Dessa forma, nessa comunidade, tudo praticamente ocupou o lugar do quantificador to$d o(s)$, enquanto nas demais o quantificador tudo está em variação com o quantificador todo. No entanto, mais pesquisas seriam necessárias para verificar essa segunda possibilidade de interpretação dos dados.

Concluo com a reflexão sobre a necessidade de estudar as variedades do PB de forma mais precisa. Para isso, o estudo sobre as variedades afro-brasileiras pode contribuir para compreender a influência das línguas africanas no PB. A relação com a perda da marca-

https://periodicos.unifap.br/index.php/letras

Macapá, v. 7, n. 2, 20 semestre, 2017. 
ção de concordância nominal ou verbal corrobora a possibilidade de analisar essas variantes como perfazendo um continuum afrobrasileiro do português (PETTER, 2009). Esse continuum, no entanto, deve ser traduzido em termos de variantes de gramaticais, em duas ou três gramáticas, a depender do caso, já que a frequência de concordância não deve ser confundida com a sintaxe dos elementos que participam dessas relações.

\section{Referências}

ANDRADE, R. K. Vissungo com Angu: Histórias e memórias da produção e consumo de fubá no Alto Jequitinhonha. Dissertação (Mestrado em História Social). Universidade Católica de São Paulo, São Paulo, 2013.

ANDRADE FILHO, J. B. de. Variação Linguística: o caso de Furnas da Boa Sorte. Dissertação (Mestrado em Linguística). Universidade Federal de Mato Grosso do Sul, Três Lagoas, 2007.

BOBALIIK, J. D. Morphosyntax: the syntax of verbal inflection. Tese (Doutorado em Linguística). Cambridge, MA: Massachussetts Institute of Technology, 1995.

BOŠKOVIĆ, ž. Now I'm a phase, now I'm not a phase: On the variability of phases with extraction and ellipsis. Linguistic Inquiry, Cambridge, MA, v. 45, n. 1, p. 27-89, jan./mar. 2014.

CRUZ, A. de S. "Os 'quantificador' tá tudo flutuando": uma análise de tudo enquanto modificador de grau no português brasileiro. Dissertação (Mestrado em Linguística). Universidade de Brasília, Brasília, 2016.

CHOMSKY, N. Lectures on Government and Binding. Dordrecht: Foris, 1981. 


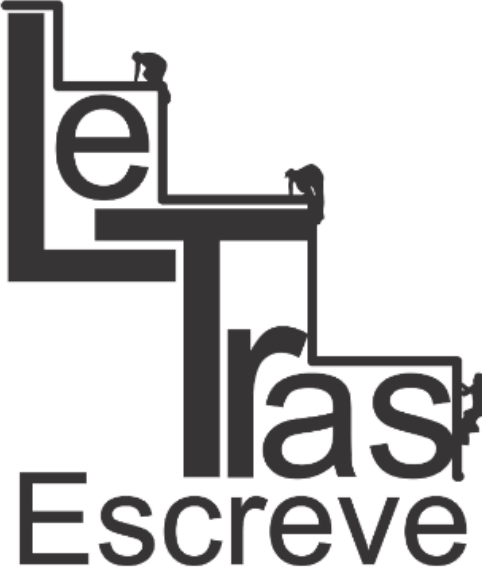

(ISSN 2238-8060)

The Minimalist Program. Cambridge, MA: The MIT Press, 1995

On Phases. In: FREIDIN, R.; OTERO, C. P.; ZUBIZARRETA, M. L.

(eds.). Foundational issues in Linguistic Theory: Essays in Honor of Jean-Roger Vergnaud. Cambridge, MA: MIT Press, 2008, p. 133-166.

FITZPATRICK, J. The syntactic and semantic roots on floating quantification. Tese (Doutorado em Linguística). Massachussetts Institute of Technology, Cambridge, MA, 2006.

GODOY, L. A. G. A palavra tudo como quantificador universal puro no Português Brasileiro. Monografia (Graduação em Letras). Universidade Federal de Minas Gerais, Belo Horizonte, 2005.

GODOY, L.; CANÇADO, M. O quantificador tudo no PB. Revista Letras, Curitiba, n. 70, p. 157-182, set./dez. 2006.

LACERDA, R. Quantificadores flutuantes no português brasileiro. Dissertação (Mestrado em Linguística). Universidade de São Paulo, São Paulo, 2012.

LUCCHESI, D.; BAXTER, A.; RIBEIRO, I. (orgs.) 0 português afrobrasileiro. Salvador: EDUFBA, 2009

OLIVEIRA, M. S. D. de; FERNANDES, J. T. V. Aspectos etnolinguísticos da fala em uma comunidade quilombola do Pará: Jurussaca. Cadernos CERU, série 2, vol. 21, n. 1, p. 13-32, jun. 2010.

PETTER, M. O continuum afro-brasileiro do português. In: GALVES, C; GARMES, H.; RIBEIRO, F. (eds.). África-Brasil: caminhos da língua portuguesa. Campinas: Editora Unicamp, 2009, p. 159-173.

PETTER, M.; OLIVEIRA, M. D. Levantamento etnolinguístico de comunidades afro-brasileiras: Minas Gerais e Pará. Projeto piloto IPHAN/USP. 2011. Disponível em: <http://www.fflch.usp.br/dl/indl/ Extra/Projeto_Iphan_USP.htm>. Acesso: 1. ago. 2012.

PIRES DE OLIVEIRA, R. O menino tá todo triste. Uma reflexão sobre a quantificação universal no PB. Revista Letras, Curitiba, n. 61, especi-

https://periodicos.unifap.br/index.php/letras Macapá, v. 7, n. 2, 20 semestre, 2017. 


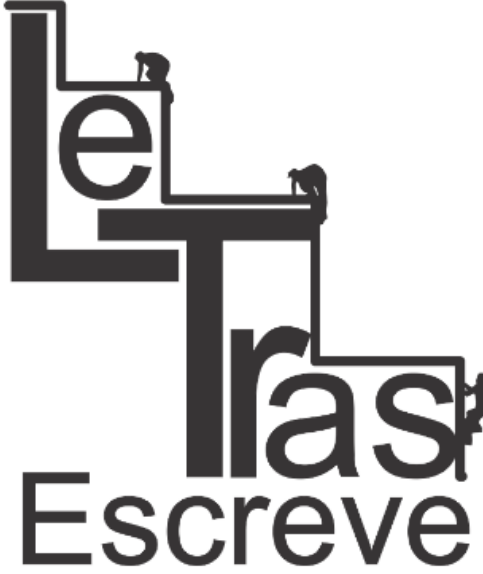

(ISSN 2238-8060) al, p. 191-210, 2003.

QUEIROZ, S. M. de M. A língua do negro da Costa: um pidgin em Minas Gerais? Revista do Centro de Estudos Portugueses, Belo Horizonte, vol. 13, n. 15, p. 94-105, jan./jun. 1993.

SACCONI, L. A. Não erre mais! Mais de 10.000 casos, corrigidos, comentados e explicados. 12. ed. São Paulo: Atual, 1990.

SEDRINS, A. P. A posição do quantificador TODOS no sintagma nominal do português brasileiro. In: BORBA, V. C. M.; CARVALHO, M. L. G. C.; LIMA, G. O. S. (orgs.). Contribuições para a pesquisa em linguística nas diferentes áreas: partilhando reflexões e resultados. Maceió: Edufal, 2009, p. 151-173.

SILVA, J. F. C. da. O português afro-indígena de Jurussaca/PA: revisitando a descrição do sistema pronominal pessoal da comunidade a partir da textualidade. Tese (Doutorado em Filologia e Língua Portuguesa). Universidade de São Paulo, São Paulo, 2014.

SPORTICHE, D. A theory of floating quantifiers and its corollaries for constituent structure. Linguistic Inquiry, vol. 19, n. 3, p. 425-449, jul./set. 1988.

TRANNIN, J. B. Tudo na história do português. Tese (Doutorado em Linguística). Universidade Estadual de Campinas, Campinas, 2016.

VICENTE, H. S. G. O quantificador flutuante todos no português brasileiro e no inglês: uma abordagem gerativa. Tese (Doutorado em Linguística) Universidade de Brasília, Brasília, 2006.

VICENTE, H. S. G.; GOMES, A. P. Q. Um tratamento unificado de grau para o quantificador flutuante e o intensificador todo. Revista Linguística, Rio de Janeiro, vol. 9, n. 1, p. 112-132, jun. 2013.

\section{Artigo recebido em 19/05/2017}

Aceito em 27/03/2018 